\title{
Use of a modified angioplasty balloon catheter in the dilatation of tight biliary strictures
}

\author{
K J M Rao, H Blake, A Theodossi
}

\begin{abstract}
Nineteen biliary strictures were dilated using a modified angioplasty balloon catheter to allow insertion of a $10 \mathrm{~F}$ prosthesis. In each instance biliary strictures were successfully dilated which had previously been too tight to widen with standard endoscopic biliary dilating catheters. Eleven patients had malignant hilar strictures, four malignant distal common bile duct strictures, and four benign strictures. There were no complications as a result of the procedure and satisfactory biliary drainage was established in all patients. We conclude that tight biliary strictures can be successfully dilated using a modified angioplasty balloon catheter.
\end{abstract}

Endoscopic insertion of a prosthesis to drain a malignant biliary obstruction appears to be just as effective as a surgical bypass procedure. ${ }^{1-3}$ In addition a recent trial indicates that the endoscopic approach may be safer. ${ }^{1}$ In addition to the usual endoscopic difficulties experienced in selectively cannulating the biliary tree ${ }^{4}$ we have found that one of the major obstacles to successful insertion of a biliary prosthesis is the resist-

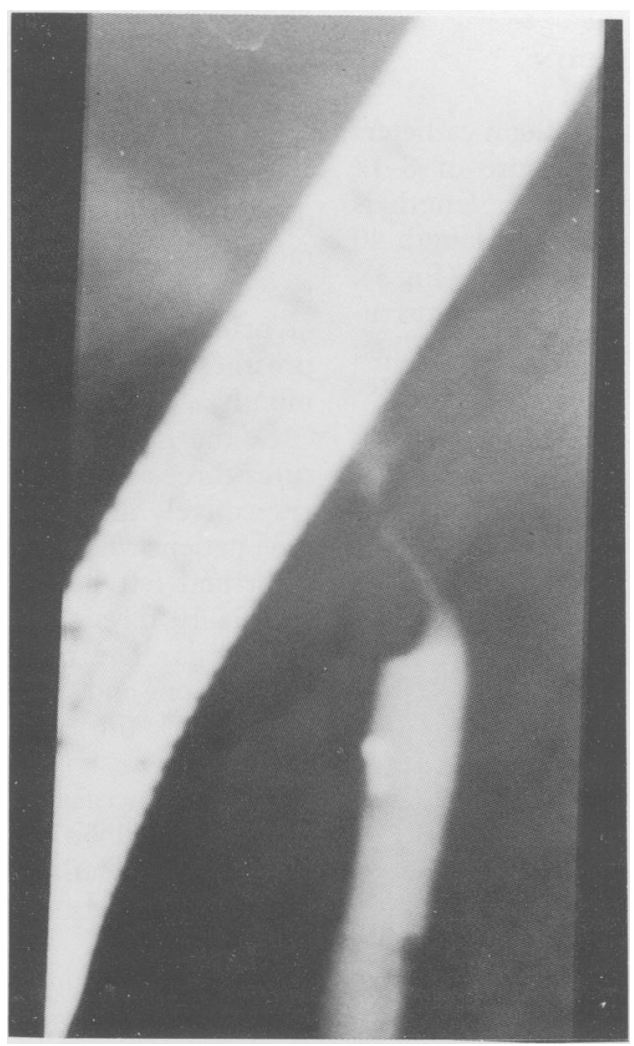

Figure 1: Cholangiogram showing marked mid common bile duct stricture. ance to dilatation of very tight biliary strictures despite the use of standard biliary dilators. In the past year we have investigated the value of the Olbert endoscopic balloon dilating catheter ${ }^{\star}$ for dilating biliary strictures which we found impossible to dilate using standard biliary dilators.

\section{Methods}

\section{PATIENTS}

Over a 12 month period we dilated very tight biliary strictures in 19 patients ( 13 women). The mean age was 68 years, range 31 to 93 . All patients were shown to have mechanical obstruction of the biliary tree by ultrasound examination. The nature and the site of the obstruction were further clarified by detailed cholangiography during endoscopic retrograde cholangiopancreatography (ERCP). Of the 15 patients with malignant biliary obstruction 11 had hilar lesions and the remaining four had lower common bile duct strictures. Four patients had benign strictures.

The patients were admitted the day before the procedure. After obtaining informed consent from each patient, the platelet count, white cell count, and prothrombin time were measured and $2 \mathrm{U}$ blood were cross matched. Ampicillin

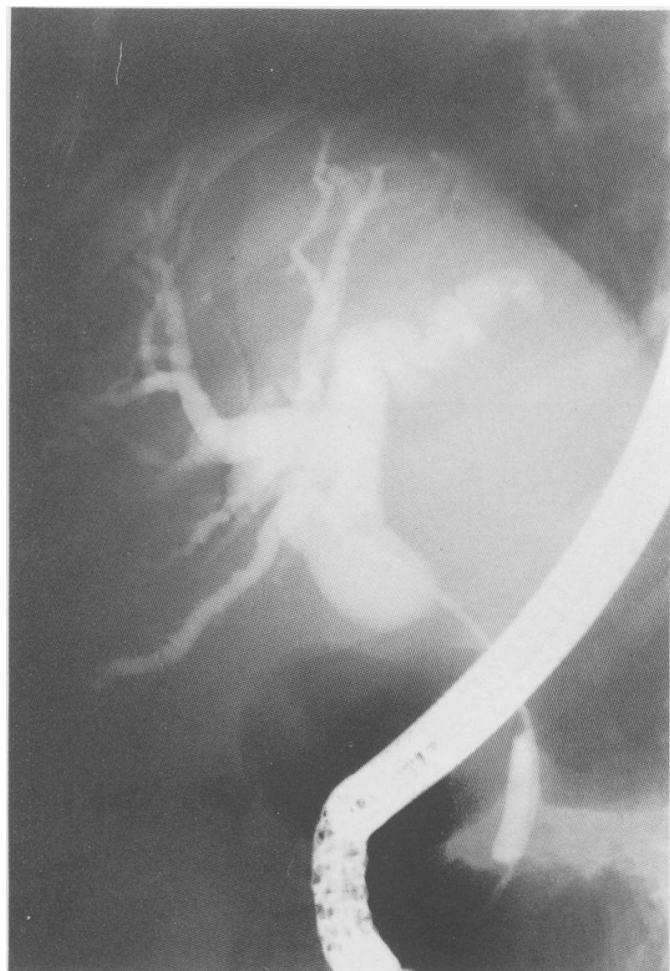

Figure 2: The same cholangiogram illustrating a 5.5 French guiding catheter across the stricture.
Correspondence to:

Dr Andrew Theodossi, Mayday Hospital, Thornton Heath, Surrey CR4 7YE.

Accepted for publication

^Meadox (UK) Ltd, Mathe House, Mathew Street, Dunstable, 


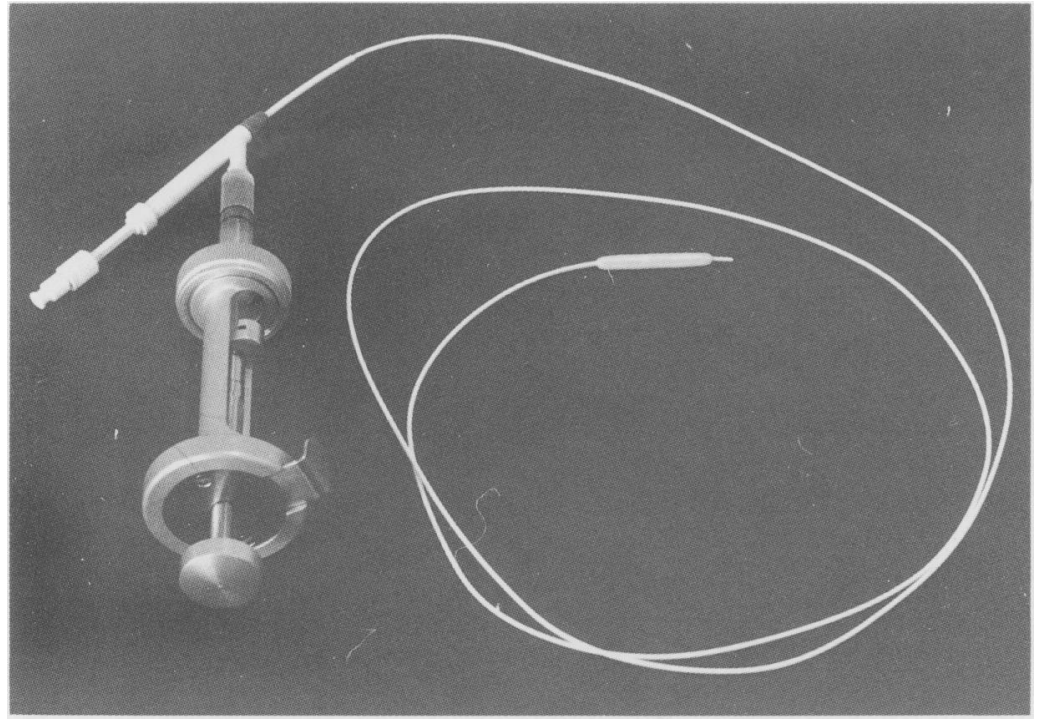

Figure 3: The Olbert endoscopic balloon dilating catheter system.

and gentamicin were given one hour before and for 24 hours after the procedure. Endoscopic retrograde cholangiopancreatography, together with a small papillotomy were undertaken as previously described. ${ }^{45}$

We used the Olympus OES TJF 10 side viewing duodenoscope, and after demonstrating the stricture radiologically (Fig 1 ) an $0.35 \mathrm{~mm}$ Teflon coated guide wire was passed through the stricture as previously described (Fig 2). ${ }^{6}$ In two patients it was not possible to pass the guide wire through the stricture by the endoscopic route. The guide wire was successfully passed percutaneously and then the end of the guide wire was picked up by an endoscopic snare and pulled through the endoscope. ${ }^{67}$

\section{OLBERT ENDOSCOPIC BALLOON}

DILATING CATHETER SYSTEM

This is a modified angioplasty balloon catheter, which can be inflated to a pressure of 8-12 atmospheres ${ }^{8}$ by fluid. The catheter length is $180 \mathrm{~cm}$, shaft size 6 French, balloon length 40 $\mathrm{mm}$ and balloon inflated diameter $6 \mathrm{~mm}$ (Fig 3). The balloon can be passed through the instrument channel of the duodenoscope. When deflated the balloon lies flush with the catheter

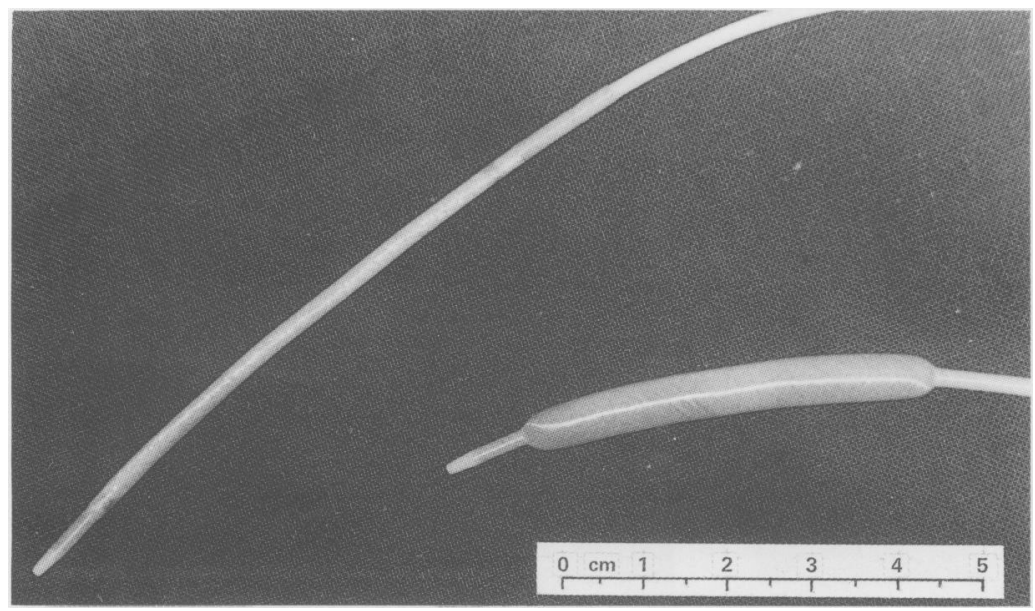

Figure 4: Balloon-deflated and inflated. shaft (Fig 4). As it is inflated with contrast medium the inflated segment can be clearly seen in relation to the strictured segment of the biliary tree on fluoroscopy.

In each instance we tried to dilate the stricture with standard dilating catheters, but it was not possible to pass a catheter larger than 6 French diameter. An Olbert balloon catheter was then fed over the guide wire and positioned across the stricture using fluoroscopy (Fig 5). The balloon was then inflated with half strength Conray 280 using a $5 \mathrm{ml}$ syringe mounted in a specially made metallic inflation handle. The balloon was then inflated to a pressure of 8-12 atmospheres and it was seen to fill under fluoroscopic control. The balloon was left inflated for three minutes and the narrowed part of the balloon could be seen to dilate at the end of the three minutes interval (Fig 6). After removing the Olbert balloon, a 6 French guiding catheter was then fed over the guide wire, then a 10 French dilating catheter was passed down the endoscope over the 6 French catheter and through the stricture. The 10 French dilating catheter was then removed and the prosthesis was pushed down over the 6 French catheter using the 10 French pusher as previously described. ${ }^{4}$ In six of the malignant strictures the Olbert balloon with a diameter of $8 \mathrm{~mm}$ had to be used because the $6 \mathrm{~mm}$ balloon did not give sufficient dilatation to allow passage of a 10 French dilating catheter.

\section{Results}

Tight biliary strictures were successfully widened by the modified angioplasty balloon catheter and biliary endoprostheses were then inserted in 19 patients. At the end of the procedure, bile was seen to flow freely into the duodenum in each instance. Symptoms were improved and no complications related to the procedure were seen in the 19 patients. All of the patients with benign strictures, as anticipated, are alive and well without jaundice.

Of the four patients with distal common bile duct strictures, two have died four and five months respectively after insertion of their prostheses. One patient is alive without jaundice or pruritus eight months after insertion of the prosthesis and the other patient is alive after one month.

Of the 11 patients with malignant hilar strictures three are alive one, six, and seven months respectively after insertion of their prostheses. One patient who had marked narrowing of both right and left hepatic ducts, died from septicaemia 10 days after insertion of a 10 French prosthesis. The remaining seven patients died between one and six months after insertion of the prosthesis, the median survival being two months.

On three occasions we were unable to deflate the reused balloon by the recommended method. By cutting the catheter proximally, however, the balloon was successfully deflated and removed.

\section{Discussion}

Drainage of malignant obstruction of the biliary tree by endoscopic insertion of a biliary prosthe- 
Figures 5 and 6: Inflated Olbert balloon placed across the stricture.

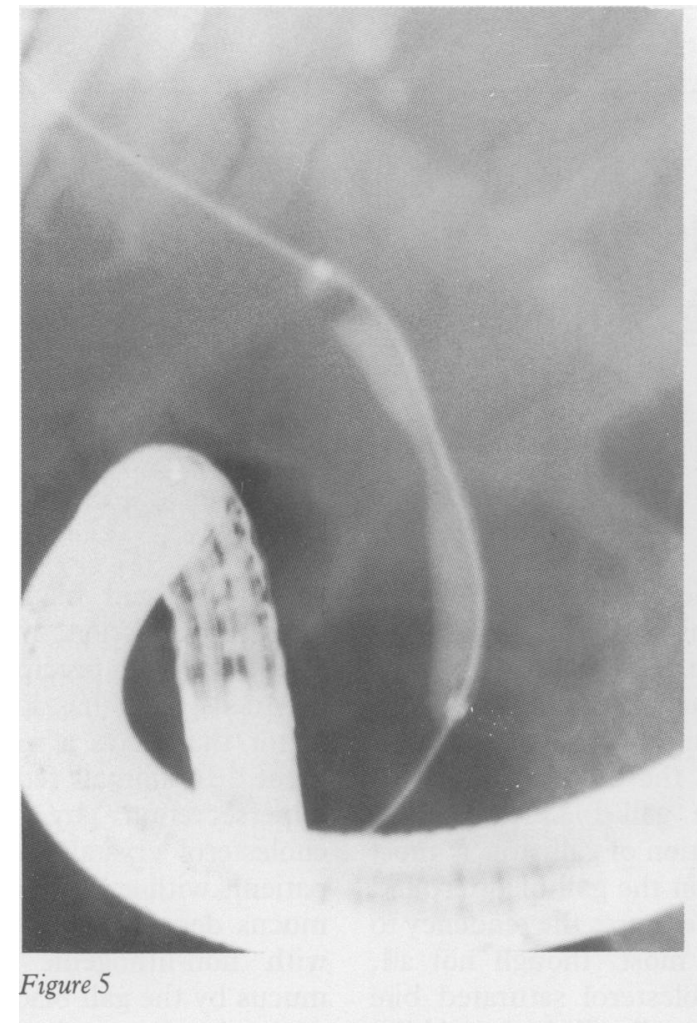

sis is a widely accepted therapeutic technique. It is especially useful in elderly patients who may not be fit for surgery. Insertion of an endoprosthesis may be difficult in patients with biliary strictures. Many observers advocate the use of graded biliary dilators to stretch tight biliary strictures. In addition, in our experience, air inflated balloon dilators have rarely been successful in dilating tight malignant biliary strictures sufficiently to allow insertion of a $10 \mathrm{~F}$ prosthesis. This is especially true for malignant hilar strictures. We have found that repeated passage of dilating catheters tend to kink or displace a narrow guide wire. The rounded tip of the Olbert balloon makes its insertion easier through the narrow strictures. The major advantage of this balloon is that it lies flush with the catheter when deflated (Fig 4) and this makes it easier to pass the balloon through tight strictures. In a previous study only two patients had their malignant biliary strictures successfully dilated by an angioplasty balloon catheter. ${ }^{9}$ As the balloon described in that study could only be inflated to 5 atmospheres pressure, we believe that the Olbert balloon should be more effective as it can be inflated to 12 atmospheres pressure, but to our knowledge a comparison of these balloons has not been attempted. When filled with fluid the Olbert balloon is harder than an ordinary air filled balloon catheter. It has only longitudinal elasticity hence it is unlikely to

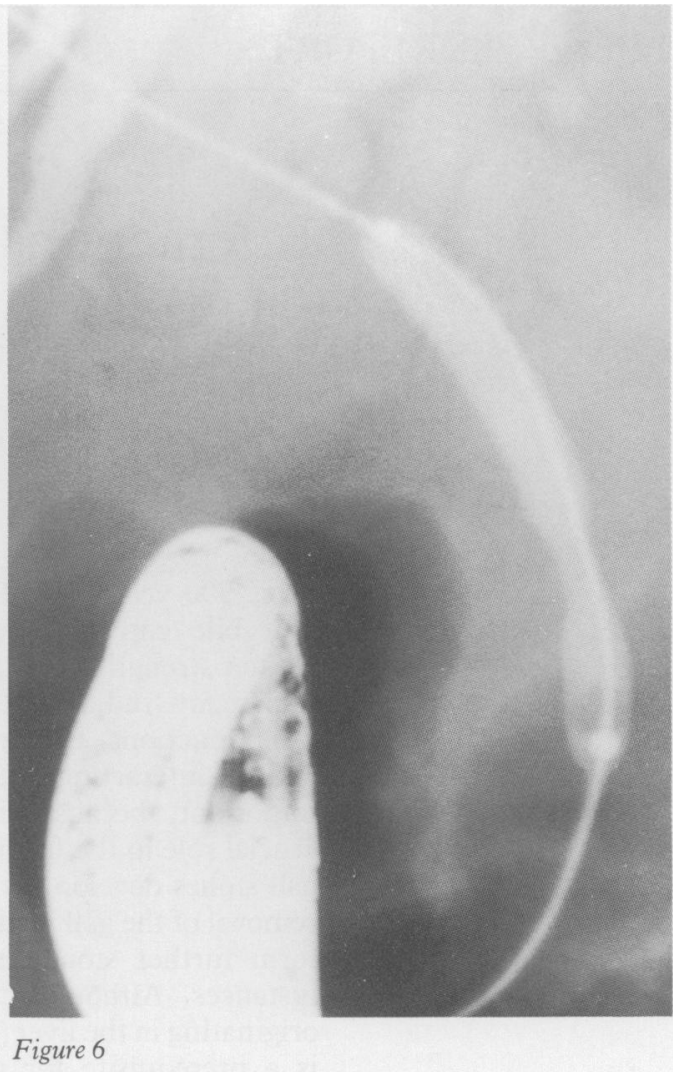

perforate the stricture. The manufacturers recommend the balloon for a single use but we have resterilised and reused it without any complications. Clearly this action is controversial and requires more research and discussion. The nursing staff especially found this system easy to use. We found the Olbert balloon quick, safe, effective and easy to use in dilatation of tight biliary strictures.

1 Dowsett JF, Russell RCG, Hatfield ARW, et al. Malignant obstructive jaundice: what is the best management? prospective randomised trial of surgery $v$ endoscopic stenting [Abstract]. Gut 1988; 29: A1493.

2 Leung JWC, Emery R, Cotton PB, et al. Management of malignant obstructive jaundice at the Middlesex hospital malignant obstructive jau

3 Huibregtse $\mathrm{K}$, Tytgat GN. Palliative treatment of obstructive jaundice by transpapillary introduction of large bore bile duct jaundice by transpapillary introductio

4 Cotton PB. Duodenoscopic placement of biliary prosthesis to relieve malignant obstructive jaundice. $B r \mathcal{F}$ Surg 1982; 69: 501-3.

5 Cotton PB. Progress report ERCP. Gut 1977; 20: 316-41.

6 Shorvan PJ, Cotton PB, Mason RR, et al. Percutaneous transhepatic assistance for duodenoscopic sphincterotomy Gut 1985; 26: 1373-6.

7 Robertson DAF, Hacking CN, Birch S, et al. Experience with combined percutaneous and endoscopic approach to sten insertion in malignant obstructive jaundice. Lancet 1987; ii: $1449-52$.

8 Olbert F, Muzika N. Dilatation and the expanding balloon catheter. In: Dotter, CT, Gruntzig A, Schoop W, Zeitler E. Percutaneous transluminal angioplasty. Berlin: SpringerVercutaneous 1983: 37-45.

9 Siegel JH, Guelrud M. Endoscopic cholangiopancreatoplasty: hydrostatic balloon dilatation in the bile duct and pancreas. hydrostatic balloon dilatation in the
Gastrointest Endosc 1983; 2: 99-103. 